\title{
Molecular Genetic Analysis of Cucumber mosaic virus Populations Infecting Pepper Suggests Unique Patterns of Evolution in Korea
}

\author{
Mi-Kyeong Kim, Jang-Kyun Seo, Hae-Ryun Kwak, Jeong-Soo Kim, Kook-Hyung Kim, \\ Byeong-Jin Cha, and Hong-Soo Choi
}

First, second, third, and seventh authors: Crop Protection Division, National Academy of Agricultural Science, Rural Development Administration, Suwon 441-707, Korea; first and sixth authors: Department of Plant Medicine, Chungbuk National University, Cheongju 361-763, Korea; fourth author: Department of Plant Medicine, Andong National University, Andong 760-749, Korea; and fifth author: Department of Agricultural Biotechnology and Plant Genomics and Breeding Institute, Seoul National University, Seoul 151-921, Korea. Accepted for publication 23 February 2014.

\begin{abstract}
Kim, M.-K., Seo, J.-K., Kwak, H.-R., Kim, J.-S., Kim, K.-H., Cha, B.-J., and Choi, H.-S. 2014. Molecular genetic analysis of Cucumber mosaic virus populations infecting pepper suggests unique patterns of evolution in Korea. Phytopathology 104:993-1000.

Studying genetic structure and diversity of viruses is important to understand the evolutionary mechanisms that generate and maintain variations in viral populations. Cucumber mosaic virus (CMV) is endemic in most pepper fields in Korea. Currently, no effective methods for control of CMV are available due to many environmental and biological factors such as the extensive evolutionary capacity of CMV. Thus, analyzing the genetic structure of CMV populations may facilitate

pepper (Capsicum annuит) samples showing virus symptoms were collected by field surveys performed throughout Korea in 2007. Reversetranscription polymerase chain reaction analyses revealed that, in total, 165 collected samples were infected with CMV. Forty-five CMV isolates were randomly selected within each regional subpopulation and analyzed by full-genome sequencing. Analyses of genetic diversity showed that the $2 \mathrm{~b}$ gene of CMV is under weaker purifying selection than the other genes. Based on the phylogenetic analysis of RNA1, the CMV isolates from pepper were divided into three clusters in subgroup I. Our full-genome sequence-based molecular analyses of the CMV Korean population suggest that the subpopulations of CMV have been geographically localized in pepper fields in Korea.
\end{abstract} the development of strategies for the control of CMV. In this study, 252
Pepper (Capsicum annuum L.) is an economically important vegetable crop worldwide. Pepper is broadly used as a spice and flavor ingredient in Korea. Although consumption of pepper is increasing, viral diseases often cause epidemics in pepper in Korea. Viral diseases usually induce severe symptoms on pepper fruit, such as stunting, necrosis, malformation, and mosaic, resulting in a significant loss of the yield and commercial value $(1,4,18)$.

At least 10 families of plant viruses (i.e., Partitiviridae, Bromoviridae, Comoviridae, Tombusviridae, Luteoviridae, Bunyaviridae, Potyviridae, Geminiviridae, Rhabdoviridae, and Virgaviridae) are known to infect pepper worldwide $(3,12)$. In Korea, many viruses have been reported to infect pepper $(3,4,18,21)$. The list includes Cucumber mosaic virus (CMV), Broad bean wilt virus 2 (BBWV2), Pepper mottle virus (PepMoV), Pepper mild mottle virus (PMMoV), Pepper severe mosaic virus, Bell pepper mottle virus (BPMV), Pepper vein mottle virus, Pepper vein chlorosis virus, and Potato virus $X$ (21). Viral disease caused by CMV has occurred most frequently and caused the most severe damage to pepper plants in Korea $(3,4,18)$.

CMV, the type member of the genus Cucumovirus, is an isometric virus with a tripartite genome of positive-sense, singlestranded RNA (28). CMV is distributed worldwide, has the widest host range, and is transmitted by $>60$ aphid species in a nonpersistent manner $(13,28)$. CMV can be divided into two major subgroups, I and II, based on the sequence similarity and serological relationships, and subgroup I can be further divided into

Corresponding authors: H.-S. Choi; E-mail address: hschoi@korea.kr and B.-J. Cha; E-mail address: bjcha@ chungbuk.ac.kr

http://dx.doi.org/10.1094/PHYTO-10-13-0275-R

(C) 2014 The American Phytopathological Society subgroups IA and IB (13,28,31). Several studies have analyzed the genetic structure of CMV populations in Spain, California, and Italy based on RNase protection assays (RPAs) and analyses of partial genomic sequences $(5,8,9,24,25)$. A recent review has described population genetics of CMV on a global scale and noted the importance of analyzing sequences of all three genome segments of CMV to better understand population genetics of CMV (13).

Studying genetic structure and diversity of viruses is important to understand their molecular evolutionary histories in relation to virulence, dispersion, and emergence of epidemics. CMV is endemic in most pepper fields in Korea $(3,4,18)$. Currently, the only effective control of CMV is considered to be through genetic resistance. The durability of resistance against plant viruses is highly related to evolutionary potential of viruses (11). Thus, analyzing the molecular genetic structure of CMV populations infecting pepper may facilitate the development of strategies for the control of CMV. In the present study, we determined full genome sequences of $45 \mathrm{CMV}$ isolates from naturally infected pepper plants in Korea. We examined the genetic structure and diversity of this CMV population by comparison with previously reported sequences of $13 \mathrm{CMV}$ strains and Peanut stunt virus (strain ER) based on analyses of complete genome sequences.

\section{MATERIALS AND METHODS}

Virus isolates and reverse-transcription polymerase chain reaction. In total, 252 pepper (C. annuum) samples showing typical virus symptoms were collected in commercial pepper fields in Korea during the summer of 2007. To identify viruses from the pepper tissues, total RNAs were extracted from the collected samples and subjected to reverse-transcription polymerase chain 
reaction (RT-PCR) analyses using specific primers for CMV (5'AAGAARCTTGTTTCGCGCATT-3' and 5'-TGGTCTCCTTT TRAGGCCCCCA-3'), BBWV2 (5'-AAACAAACAGCTTTCG TTCCG-3' and 5'-GCCATCTCATTGGCATGGA-3'), or PepMoV (5'-AATGGCACGTCCCCAAA-3' and 5'-TCTCTCTCATGCC AACTACGA-3'). PCR reaction was performed using GoTaq DNA polymerase (Promega Corp., Madison, WI) under the following conditions: initial denaturation at $94^{\circ} \mathrm{C}$ for $2 \mathrm{~min}$; and 35 cycles consisting of $20 \mathrm{~s}$ at $94^{\circ} \mathrm{C}, 30 \mathrm{~s}$ at $50^{\circ} \mathrm{C}$, and $60 \mathrm{~s}$ at $72^{\circ} \mathrm{C}$. The resulting PCR products were subjected to sequencing to confirm whether the target viruses were specifically amplified.

Cloning and sequencing. Forty-five CMV isolates were randomly selected for each geographic region to examine the population genetics of CMV infecting pepper, and their complete genome sequences were determined (Fig. 1). Total RNAs extracted from the CMV-infected tissues were subjected to RT-PCR to amplify full-length genomic RNA1, RNA2, and RNA3 cDNAs using specific primer pairs (5'-GTTTATTTACAAGAGCGTACG GTT-3' and 5'-TGGTCTCCTTTAGGAGGCCC-3' for RNA1 and RNA2, and 5'-GTAATCTTACCACTGTGTGTGT-3' and 5'TGGTCTCCTTTGAGAGACCC- $3^{\prime}$ for RNA3). The $5^{\prime}$ and $3^{\prime}$ end sequences of CMV RNAs were determined by a $5^{\prime}$ and $3^{\prime}$ rapid amplification of cDNA ends (RACE) protocol (Boehringer Mannheim, Mannheim, Germany) using specific primer pairs Xecprimer (5'-AAAGAATTCCCCCCCCCCCCC-3') and 5'-TCCTT TATCGCCGTGGGAGGCTAC-3' for the $5^{\prime}$ end of RNA1, Xecprimer and $5^{\prime}$-TCCTCGGGAGTGTCGACACC- $3^{\prime}$ for the $5^{\prime}$ end of RNA3, Xec and 5'-CCTACTGGTACCTTGGAAAGCCAT-3' for the $5^{\prime}$ end of RNA3, Anchor-primer (5'-GACCACG CGTATCGATGTCGACTTTTTTTTTTTTTTTTV-3') and 5'TTGCTCGTGCTTAGCGG-3' for the $3^{\prime}$ end of RNA1, Anchorprimer and 5'-ACAAAGTCCCAGCGAGAG-3' for the $3^{\prime}$ end of RNA2, and Anchor-primer and 5'-TTGATTCTACCGTGTGGG TGACAGT-3' for the $3^{\prime}$ end of RNA3. PCR reaction was performed as described above using appropriate primer pairs. The resulting PCR fragments were cloned in pGEM-T easy vector (Promega Corp.) and were sequenced by the dideoxynucleotide termination method using various specific primers (the compo- sition of the primers used in DNA sequencing is available upon request). Subsequently, more than three clones for each fragment were completely sequenced. To verify sequence discords among the clones and identify the dominant sequence in the viral population, direct sequencing of RT-PCR products of entire genomes was performed. The nucleotide sequence data have been submitted to GenBank database with accession numbers listed in Table 1.

Sequence analyses. Multiple alignments for the CMV sequences were obtained using the ClustalX2 program and manually edited using MacClade $4.0(22,26)$. Nucleotide and deduced amino acid sequence similarities were analyzed using AlignX implemented in the Vector NTI Suite (Invitrogen, Carlsbad, CA). Pairwise genetic distances and pairwise synonymous $(d S)$ and nonsynonymous $(d \mathrm{~N})$ substitutions were analyzed by Kimura's two-parameter method (19) and the Pamilo-Bianchi-Li method $(23,29)$, respectively, using the MEGA5 program (32). The phylogenetic relationships of the CMV sequences were analyzed by the maximum likelihood (ML) method (Tamura-Nei model) implemented in the MEGA5.1 program using Peanut stunt virus (PSV) strain ER as an outgroup. Bootstrap values were calculated using 1,000 random replications. The calculated trees were displayed using the MEGA5.1 program. Spatial analyses of molecular variance (SAMOVAs) were performed using the SAMOVA 1.0 program, as described previously $(7,14)$. For SAMOVAs, 100 initial conditions were used as recommended (7) and the population indexes $\mathrm{F}_{\mathrm{SC}}, \mathrm{F}_{\mathrm{ST}}$, and $\mathrm{F}_{\mathrm{CT}}$, quantifying variations within populations, between populations, and between groups, respectively, were calculated. Positive selection at individual codons was statistically examined by the fixed-effects likelihood (FEL) and mixedeffects model of evolution (MEME) methods available from the DATAMONKEY server (http://www.datamonkey.org).

\section{RESULTS}

The appearance of viral infection in pepper in Korea. Field surveys were performed throughout Korea in 2007. We sampled pepper tissues showing typical virus symptoms such as mosaic,



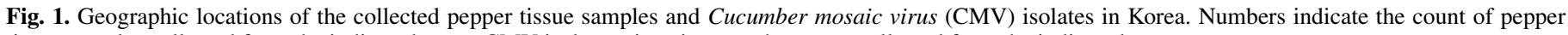
tissue samples collected from the indicated areas. CMV isolates given in parentheses are collected from the indicated areas. 
mottling, vein clearing, malformation, and local chlorosis. In total, 252 pepper tissue samples were collected from 22 areas in Korea (Fig. 1). To identify viruses from the collected pepper tissues, we performed RT-PCR using specific primers for CMV, BBWV2, or PepMoV because these three viruses are prevalent in pepper plants in Korea $(3,4,18)$. Out of 252 collected samples, 233 samples $(92.5 \%)$ were infected with at least one of the three viruses and 55,20 , and 1 samples were singly infected with BBWV2, CMV, and PepMoV, respectively. Infection with BBWV2 was detected in 205 samples $(81.3 \%)$, while 165 samples $(65.5 \%)$ were infected with CMV. Mixed infection of CMV and BBWV2 was detected in 138 samples (54.8\%) and this double infection, which causes severe damage on pepper by synergistic symptom expression, was most prevalent in pepper fields in Korea. Infection with PepMoV was detected in 92 samples $(36.5 \%)$ and 12 and 7 samples were doubly infected with PepMoV + BBWV2 and PepMoV + CMV, respectively. In addition, 72 pepper samples (28.6\%) were found to be triply infected with CMV, BBWV2, and PepMoV. Interestingly, approximately $99 \%$ of PepMoV-infected samples were mixed-infections with CMV or BBWV2, suggesting that the dynamics of infection and transmission of PepMoV in pepper fields might be highly correlated with those of CMV and BBWV2.
Molecular characterization of the CMV population. CMV is endemic in Korea and has caused severe damage persistently in most pepper fields $(3,4,18)$. Thus, to examine the population of CMV infecting pepper, $45 \mathrm{CMV}$ isolates were randomly selected for each geographic region (Fig. 1) and their complete genome sequences were determined. The sequences are available in the GenBank database with the accession codes listed in Table 1.

The molecular variability of the population of CMV from pepper was examined by comparing either complete nucleotide sequences or deduced amino acid sequences of the $45 \mathrm{CMV}$ isolates. Widespread nucleotide variations were detected throughout the genome and more significant variations were observed in the $5^{\prime}$ and $3^{\prime}$ untranslated regions (UTRs) of RNA2 and the $5^{\prime}$ UTR and central intercistronic region of RNA3 (Fig. 2). Comparison of diversity of the nucleotide sequences revealed that the genomic regions of $1 \mathrm{a}, 2 \mathrm{a}$, and $2 \mathrm{~b}$ exhibited relatively high variability compared with those of the movement protein (MP) and coat protein (CP) coding regions (Fig. 2). However, when analyzing the pairwise genetic differences at $d \mathrm{~N}$ and $d \mathrm{~S}$ nucleotide positions, the $d \mathrm{~N} / d \mathrm{~S}$ ratio of the $2 \mathrm{~b}$ coding region was significantly higher than those of the other genomic regions (Table 2). Interestingly, the genomic region of 1a exhibited the lowest $d \mathrm{~N} / d \mathrm{~S}$ ratio despite exhibiting the highest nucleotide diversity

TABLE 1. Pepper Cucumber mosaic virus isolates used in this work and GenBank accession numbers

\begin{tabular}{|c|c|c|c|c|c|}
\hline \multirow[b]{2}{*}{ Province } & \multirow[b]{2}{*}{ Area } & \multirow[b]{2}{*}{ Isolate } & \multicolumn{3}{|c|}{ Accession number } \\
\hline & & & RNA1 & RNA2 & RNA3 \\
\hline \multirow[t]{8}{*}{ Gyeonggi } & Pocheon (PC) & RP10 & KC527784 & KC527694 & KC527739 \\
\hline & & RP11 & KC527785 & KC527695 & KC527740 \\
\hline & & RP12 & KC527786 & KC527696 & KC527741 \\
\hline & & RP13 & KC527787 & KC527697 & KC527742 \\
\hline & Suwon (SW) & RP4 & KC527778 & KC527688 & KC527733 \\
\hline & & RP5 & KC527779 & КС527689 & KC527734 \\
\hline & & RP6 & KC527780 & KC527690 & KC527735 \\
\hline & Yeoju (YJ) & RP29 & KC527802 & KC527712 & KC527757 \\
\hline \multirow[t]{9}{*}{ Chungnam } & Cheongyang (CY) & RP7 & KC527781 & KC527691 & KC527736 \\
\hline & & RP3 & KC527777 & KC527687 & KC527732 \\
\hline & & RP14 & KC527788 & KC527698 & KC527743 \\
\hline & & RP15 & KC527789 & KC527699 & KC527744 \\
\hline & & RP16 & KC527790 & KC527700 & KC527745 \\
\hline & & RP17 & KC527791 & KC527701 & KC527746 \\
\hline & Seosan (SS) & RP42 & KC527812 & KC527722 & KC527767 \\
\hline & & RP44 & KC527813 & KC527723 & KC527768 \\
\hline & & RP45 & KC527814 & KC527724 & KC527769 \\
\hline \multirow[t]{7}{*}{ Chungbuk } & Boeun (BE) & RP38 & KC527808 & KC527718 & KC527763 \\
\hline & & RP39 & KC527809 & KC527719 & KC527764 \\
\hline & & RP40 & KC527810 & KC527720 & KC527765 \\
\hline & & RP41 & KC527811 & KC527721 & KC527766 \\
\hline & Chungju (CJ) & RP34 & KC527806 & KC527716 & KC527761 \\
\hline & & RP35 & KC527807 & KC527717 & KC527762 \\
\hline & Danyang (DY) & RP24 & KC527797 & KC527707 & KC527752 \\
\hline \multirow[t]{4}{*}{ Jeonbuk } & Buan (BA) & RP18 & KC527792 & KC527702 & KC527747 \\
\hline & & RP19 & KC527793 & KC527703 & KC527748 \\
\hline & Muju (MJ) & RP8 & KC527782 & KC527692 & KC527737 \\
\hline & & RP9 & KC527783 & KC527693 & KC527738 \\
\hline \multirow{2}{*}{ Jeonnam } & Naju (NJ) & RP1 & KC527775 & KC527685 & KC527730 \\
\hline & & $\mathrm{RP} 2$ & KC527776 & KC527686 & KC527731 \\
\hline \multirow[t]{3}{*}{ Gangwon } & Yanggu (YG) & RP20 & KC527794 & KC527704 & KC527749 \\
\hline & Pyeongchang (PCh) & $\mathrm{RP} 22$ & KC527795 & KC527705 & KC527750 \\
\hline & & $\mathrm{RP} 23$ & KC527796 & KC527706 & KC527751 \\
\hline \multirow[t]{7}{*}{ Gyeongbuk } & Chilgok (CG) & RP48 & KC527817 & KC527727 & KC527772 \\
\hline & & RP49 & KC527818 & KC527728 & KC527773 \\
\hline & & RP50 & KC527819 & KC527729 & KC527774 \\
\hline & Yeongju (YJu) & RP25 & KC527798 & KC527708 & KC527753 \\
\hline & & RP26 & KC527799 & KC527709 & KC527754 \\
\hline & Uiseong (US) & RP27 & KC527800 & KC527710 & KC527755 \\
\hline & & RP28 & KC527801 & KC527711 & KC527756 \\
\hline \multirow[t]{5}{*}{ Gyeongnam } & Hadong (HD) & RP46 & KC527815 & KC527725 & KC527770 \\
\hline & & RP47 & KC527816 & KC527726 & KC527771 \\
\hline & Geochang (GC) & RP30 & KC527803 & KC527713 & KC527758 \\
\hline & & RP31 & KC527804 & KC527714 & KC527759 \\
\hline & & RP33 & KC527805 & KC527715 & KC527760 \\
\hline
\end{tabular}


(Table 2). In all, the results suggested that $2 \mathrm{~b}$ of CMV is under weaker purifying selection than the other genes in the CMV population.

Genetic structure of the CMV population. We performed phylogenetic analyses to determine the relationships among CMV isolates from pepper by including the reported sequences of 13 CMV strains and isolates (Fig. 3). We also included an isolate of PSV (strain ER) as an outgroup in the phylogenetic analyses. The phylogenetic trees were reconstructed by the ML method based on the alignments of the complete nucleotide sequences of RNA1, RNA2, and RNA3 (Fig. 3). Phylogenetic analyses revealed that all the CMV isolates from pepper belonged to subgroup I. When the phylogenetic analyses were performed using RNA1 sequences, the CMV isolates from pepper were further split into three clusters (Fig. 3). On the other hand, in the phylogenetic trees reconstructed with RNA2 or RNA3 sequences, the CMV isolates from pepper were largely subdivided into two clusters (Fig. 3). This clustering of the CMV population from pepper was further supported by the genetic diversity analyses. The genetic diversities within and between subpopulations, which were designated based on the phylogenetic trees, were estimated by Kimura's two-parameter method (19). The analyses showed that the genetic diversities within subpopulations were somewhat low compared with those between subpopulations (Table 3).

Based on the phylogenetic analyses, we examined whether the genetic relationship is correlated with geographic location of the CMV population. Interestingly, the phylogenetic analyses performed with RNA1 sequences highly supported geographic clustering of the CMV isolates from pepper (Fig. 4). Although the CMV isolates collected from the middle inland areas of Korea fell into cluster A, the CMV isolates collected from the south and farnorth areas belonged to clusters B and C, respectively (Figs. 3 and 4). Furthermore, RNA1-based phylogenetic analyses revealed the CMV in mixed infections belonged to different subpopulations at the boundary regions (Fig. 4). To further assess the geographic

TABLE 2. Nucleotide diversity for different genomic regions of the Cucumber mosaic virus population isolated from pepper in Korea

\begin{tabular}{lcccc}
\hline & \multicolumn{4}{c}{ Nucleotide diversity $^{\mathrm{a}}$} \\
\cline { 2 - 5 } Region & $d$ & $d \mathrm{~N}$ & $d \mathrm{~S}$ & $d \mathrm{~N} / d \mathrm{~S}$ \\
\hline $1 \mathrm{a}$ & $0.060 \pm 0.003$ & $0.012 \pm 0.002$ & $0.198 \pm 0.010$ & 0.061 \\
2a & $0.049 \pm 0.003$ & $0.017 \pm 0.002$ & $0.131 \pm 0.009$ & 0.130 \\
2b & $0.048 \pm 0.007$ & $0.031 \pm 0.007$ & $0.089 \pm 0.021$ & 0.348 \\
MP & $0.029 \pm 0.003$ & $0.009 \pm 0.002$ & $0.078 \pm 0.011$ & 0.115 \\
CP & $0.032 \pm 0.004$ & $0.008 \pm 0.003$ & $0.090 \pm 0.013$ & 0.089 \\
\hline
\end{tabular}

a Values are means \pm standard error of the mean; $d=$ nucleotide diversity estimated by the Kimura's two-parameter method; $d \mathrm{~N}$ and $d \mathrm{~S}=$ nucleotide diversity at nonsynonymous and at synonymous position, respectively, estimated by the Pamilo-Bianchi-Li method. structure of the CMV population in Korea, spatial analyses of molecular variance were performed using the SAMOVA program (7). The number of groups ( $\mathrm{K}$ value) ranged between two and five. The best partitioning of the spatial genetic diversity of the CMV population was obtained when the geographic subpopulations were divided into four groups $\left(K=4 ; \mathrm{F}_{\mathrm{SC}}=0.282, P<10^{-5}\right.$; $\mathrm{F}_{\mathrm{ST}}=0.804, P<10^{-5} ; \mathrm{F}_{\mathrm{CT}}=0.726, P<10^{-5}$ ) (Table 4). The barriers between the groups of subpopulations defined by the SAMOVA analysis $(K=4)$ were represented in Figure 4 . The SAMOVA result was highly correlated with the population clustering detected in the RNA1-based phylogenetic tree (Figs. 3 and 4). In all, our results suggest that the CMV subpopulations may be geographically localized in pepper fields in Korea.

Genetic reassortment is an important evolutionary process in the diversification of CMV populations (8,13,24,25,31). A previous study examined a large number of CMV isolates by RPAs and found that genetic exchanges have occurred by segment reassortment in natural CMV populations (8). Careful examination of our phylogenetic analyses, including the phylogenetic tree of the concatenated sequences of entire genomes (i.e., RNA1 + RNA2 + RNA3) of CMV strains and isolates, also strongly indicates that reassortment has occurred in the CMV population from pepper (Fig. 3). We identified at least nine possible reassortants: for RP1 and RP2, their RNAs3 belong to cluster A in the RNA3-based tree while the other two genomic RNAs belong to cluster B in the RNA1- or RNA2-based trees; For RP10, RP11, and RP13, their RNAs1 belong to cluster $C$ in the RNA1-based tree while the other two genomic RNAs belong to cluster A in the RNA2- or RNA3-based tree; for RP15 and RP27, their RNAs1 belong to cluster B in the RNA1-based tree while the

TABLE 3. Genetic diversity of population of Cucumber mosaic virus RNA1, RNA2, and RNA3 isolated from pepper in Korea

\begin{tabular}{|c|c|c|c|}
\hline \multirow[b]{2}{*}{ Population ${ }^{\mathrm{b}}$} & \multicolumn{3}{|c|}{ Nucleotide diversity between subpopulations ${ }^{\mathrm{a}}$} \\
\hline & Cluster A & Cluster B & Cluster C \\
\hline \multicolumn{4}{|l|}{ RNA1 } \\
\hline Cluster A & $0.019 \pm 0.0015$ & & .. \\
\hline Cluster B & $0.096 \pm 0.006$ & $0.018 \pm 0.0013$ & \\
\hline Cluster C & $0.094 \pm 0.005$ & $0.077 \pm 0.004$ & $0.043 \pm 0.0025$ \\
\hline \multicolumn{4}{|l|}{ RNA2 } \\
\hline Cluster A & $0.028 \pm 0.0048$ & & $\ldots$ \\
\hline Cluster B & $0.098 \pm 0.014$ & $0.030 \pm 0.0055$ & $\ldots$ \\
\hline \multicolumn{4}{|l|}{ RNA3 } \\
\hline Cluster A & $0.010 \pm 0.0013$ & & $\ldots$ \\
\hline Cluster B & $0.075 \pm 0.008$ & $0.020 \pm 0.0021$ & $\ldots$ \\
\hline
\end{tabular}

a Pairwise genetic diversity was analyzed by the Kimura's two-parameter method using the MEGA5 program. Numeric values indicate nucleotide diversity \pm standard error.

b Genome and subpopulation. Subpopulations were designated based on the phylogenetic trees shown in Figure 3.



Fig. 2. Nucleotide and encoded amino acid sequence similarities in the Cucumber mosaic virus (CMV) population. Full-length sequences of RNA1, RNA2, and RNA3 of 45 CMV isolates from pepper were aligned by ClustalX2 and analyzed using AlignX by setting the window size to 5 to estimate sequence similarities. The similarity index ' +0.8 ' on the y-axis means that sequences are perfectly conserved. A, Genome map of CMV RNAs is shown to scale. B, Similarity profile of CMV genomic nucleotide sequences. C, Similarity profile of CMV-encoded amino acid sequences. 
other two genomic RNAs belong to cluster A in the RNA2or RNA3-based tree; and for RP26 and RP45, their RNA3s belong to cluster B in the RNA3-based tree while the other two genomic RNAs belong to cluster A in the RNA1- or RNA2-based tree (Fig. 3).

Effects of selection in the CMV population from pepper. To examine the role of natural selection in the whole CMV population (including the Korean pepper isolates and the other global isolates and strains) at the molecular level, the rate of nonsynonymous substitutions per nonsynonymous site $(d \mathrm{~N})$ and the rate of synonymous substitutions per synonymous site $(d \mathbf{S})$ were analyzed. Selection at individual codons was statistically examined by two different methods, FEL and MEME $(20,27)$. The FEL method fits codon models to each site independently and performs a likelihood ratio test to evaluate the difference between $d \mathrm{~N}$ and $d \mathrm{~S}$ (i.e., $d \mathrm{~N}>d \mathrm{~S}$ indicates positive selection, $d \mathrm{~N}<$ $d \mathrm{~S}$ indicates negative selection, $d \mathrm{~N} \approx d \mathrm{~S}$ indicates neutral evolution). The MEME method fits a codon model with two

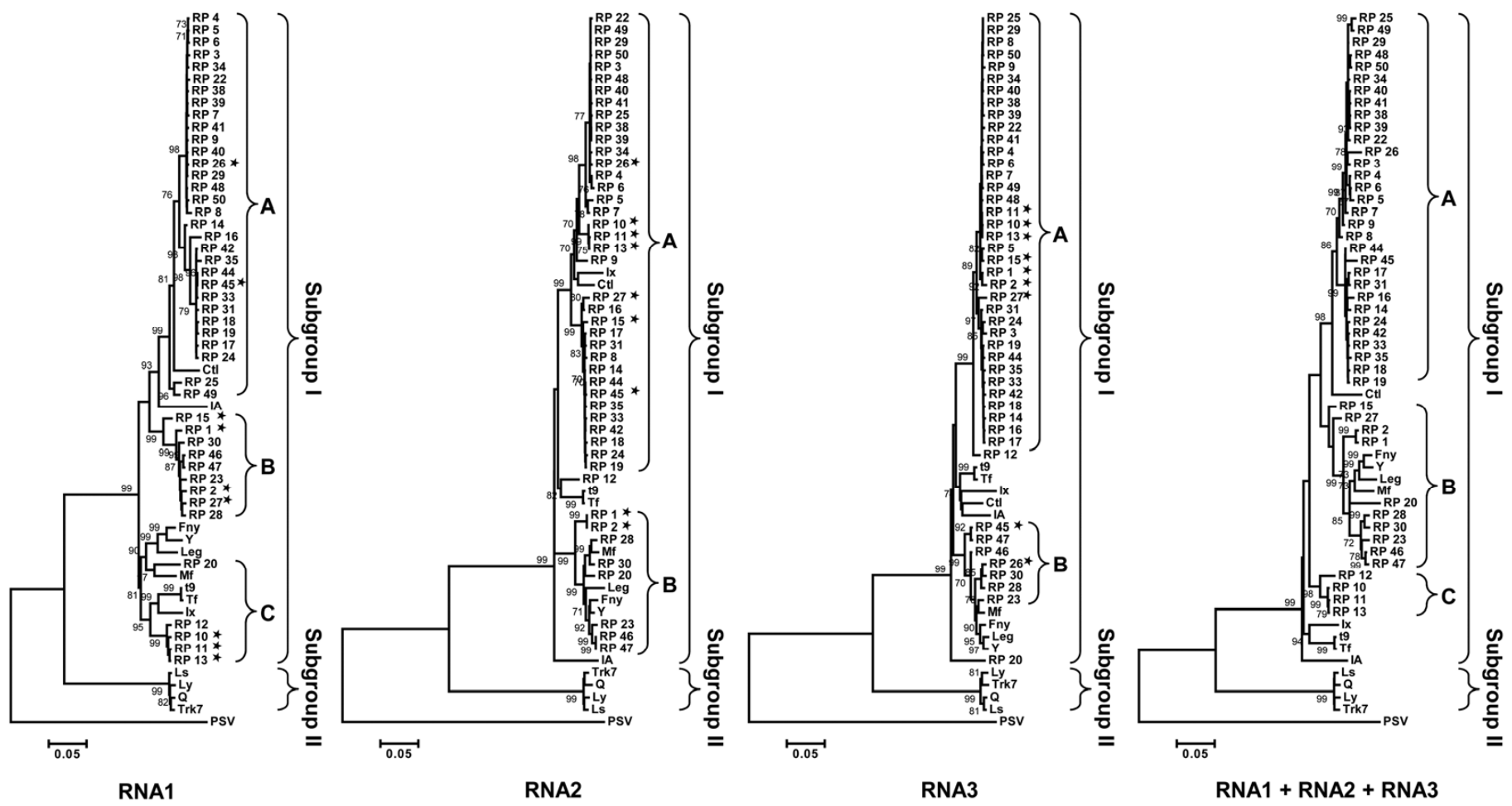

Fig. 3. Phylogenetic analyses for the complete genome sequences of RNA1, RNA2, RNA3, and RNA1 + RNA2 + RNA3 of the Cucumber mosaic virus (CMV) population. An isolate of Peanut stunt virus (PSV) was included as an out-group. Phylogenetic trees were reconstructed by the maximum-likelihood method applying the Tamura-Nei model method for nucleotide sequence analyses. Numbers on the branches indicate bootstrap percentages based on 1,000 replications (only values $>70 \%$ are shown). Possible reassortants are indicated with asterisks. GenBank accession numbers of RNA1: Fny (D00356), Leg (D16403), Y (D12537), Mf (AJ276479), IA (AB042292), Ix (U20220), Tfn (Y16924), Nt9 (D28778), CTL (EF213023), LS (AF416899), Q (X02733), Trk7 (AJ007933), LY (AF198101), and ER-PSV (U15728). GenBank accession numbers of RNA2: Fny (D00355), Leg (D16406), Y (D12538), Mf (AJ276480), IA (AB042293), Ix (U20218), Tfn (Y16925), Nt9 (D28779), CTL (EF213024), LS (AF416900), Q (X00985), Trk7 (AJ007934), LY (AF198102), and ER-PSV (U15729). GenBank accession numbers of RNA3: Fny (D10538), Leg (D16405), Y (D12499), Mf (AJ276481), IA (AB042294), Ix (U20219), Tfn (Y16926), Nt9 (D28780), CTL (EF213025), LS (AF127976), Q (M21464), Trk7 (L15336), LY (AF198103), and ER-PSV (U15730).

TABLE 4. Spatial analysis of molecular variance for the Cucumber mosaic virus population in Korea

\begin{tabular}{|c|c|c|c|c|c|}
\hline Source of variation $^{\mathrm{a}}$ & $\mathrm{df}$ & Sum of squares & Variance components & Percentage of variance $(\%)$ & $P$ value \\
\hline \multicolumn{6}{|l|}{$K=2^{\mathrm{b}}$} \\
\hline Among groups & 1 & 617.485 & 34.292 & 57.44 & $<0.001$ \\
\hline Among populations within groups & 16 & 692.910 & 12.379 & 20.73 & $<0.001$ \\
\hline Within populations & 27 & 352.917 & 13.034 & 21.83 & $<0.001$ \\
\hline \multicolumn{6}{|l|}{$K=3^{\mathrm{c}}$} \\
\hline Among groups & 2 & 853.642 & 47.119 & 69.86 & $<0.001$ \\
\hline Among populations within groups & 15 & 456.752 & 7.291 & 10.81 & $<0.001$ \\
\hline Within populations & 27 & 351.917 & 13.034 & 19.33 & $<0.001$ \\
\hline \multicolumn{6}{|l|}{$K=4^{\mathrm{d}}$} \\
\hline Among groups & 3 & 949.992 & 48.216 & 72.65 & $<0.001$ \\
\hline Among populations within groups & 14 & 360.402 & 5.118 & 7.71 & $<0.001$ \\
\hline Within populations & 27 & 351.917 & 13.034 & 19.64 & $<0.001$ \\
\hline \multicolumn{6}{|l|}{$K=5^{\mathrm{e}}$} \\
\hline Among groups & 4 & 973.326 & 47.293 & 72.27 & $<0.001$ \\
\hline Among populations within groups & 13 & 337.069 & 5.116 & 7.82 & $<0.001$ \\
\hline Within populations & 27 & 351.917 & 13.034 & 19.92 & $<0.001$ \\
\hline
\end{tabular}

${ }^{a}$ Geographic location of each population is indicated in Figure 4. $K=$ the number of groups.

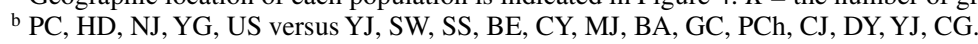

${ }^{c} \mathrm{HD}, \mathrm{NJ}$, US versus PC versus YJ, SW, SS, BE, CY, MJ, BA, GC, PCh, CJ, DY, YJ, CG, YG.

${ }^{\mathrm{d}} \mathrm{HD}, \mathrm{NJ}$, US versus PC versus YG versus YJ, SW, SS, BE, CY, MJ, BA, GC, PCh, CJ, DY, YJ, CG.

${ }^{\mathrm{e}} \mathrm{HD}$, US versus NJ versus PC versus YG versus YJ, SW, SS, BE, CY, MJ, BA, GC, PCh, CJ, DY, YJ, CG. 
categories of lineage-specific $d \mathrm{~N}$ substitution rates to each site, $\beta^{-}$ (one that is $\leq d S$ ) and $\beta^{+}$(one that is unrestricted), and calculates the proportion of branches estimated to be part of the $d \mathrm{~N}$ substitution rate class $\left(p^{+}\right)(27,33)$. We report only concordant results detected by the two methods with a stringent significance level $(P<0.05)$. Our approach identified four positively selected sites in the 1a-coding gene, three positively selected sites in the 2a-coding gene, three positively selected sites in the MP-coding gene, and one positively selected sites in the CP-coding gene (Table 5). However, no positive selection was found in the $2 b-$ coding gene in the whole CMV population.

\section{DISCUSSION}

Understanding genetic structures of virus populations and their evolutionary mechanisms is an important aspect of managing viral diseases and the risk of emerging new viruses. There have been several studies attempting to examine population genetics of CMV based on serological analyses, RPA, and analyses of partial genomic sequences $(5,8,24,25)$. However, accumulating evidence suggests that genetic exchanges by recombination and reassortment might have played an important role in CMV evolution $(13,25,31)$. This implies that more complete analyses with full

\section{(A) Isolates in Cluster A}

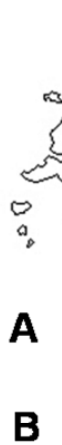

(B) Isolates in Cluster B

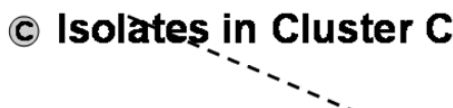

(D) Isolates in Cluster. A or $B$


$\Theta$ Isolates in Cluster $A$ or $C$
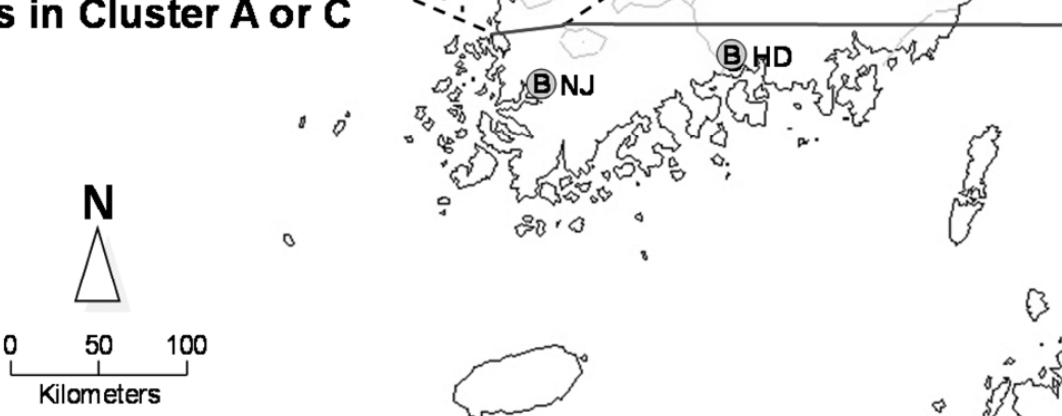

Fig. 4. Geographic distribution of the Cucumber mosaic virus (CMV) isolates in Korea. CMV isolates from pepper were clustered into three subpopulations (clusters A, B, and C) based on the phylogenetic analysis of RNA1 (Fig. 3). Whereas the CMV isolates in cluster A were prevalent throughout the middle inland areas, the CMV isolates in clusters B and C were dominant in the south and far-north areas of Korea, respectively. Barriers between the groups of subpopulations defined by spatial analyses of molecular variance $(K=4)$ are indicated with solid black lines and dotted lines.

TABLE 5. Positively selected sites in the whole Cucumber mosaic virus population, including the Korean pepper isolates and the other global isolates and strains

\begin{tabular}{|c|c|c|c|c|c|c|c|}
\hline \multirow[b]{2}{*}{$\mathrm{Gene}^{\mathrm{c}}$} & \multirow[b]{2}{*}{ Site } & \multicolumn{2}{|c|}{ FEL $^{\mathrm{a}}$} & \multicolumn{4}{|c|}{ MEME $^{\mathrm{b}}$} \\
\hline & & Normalized $d \mathrm{~N}-d \mathrm{~S}$ & $P$ value & $\beta^{-}$ & $\beta^{+}$ & $p^{+}$ & $P$ value \\
\hline \multirow[t]{3}{*}{$1 \mathrm{a}$} & 542 & 2.98 & 0.024 & 0.011 & 18.36 & 0.83 & 0.005 \\
\hline & 550 & 1.52 & 0.025 & 0 & 1.29 & 1 & 0.034 \\
\hline & 566 & 1.37 & 0.031 & 0 & 1.36 & 1 & 0.040 \\
\hline \multirow[t]{2}{*}{$2 \mathrm{a}$} & 134 & 1.95 & 0.031 & 0 & 6.30 & 1 & 0.006 \\
\hline & 139 & 2.53 & 0.009 & 0 & 1.84 & 1 & 0.015 \\
\hline & 271 & 2.89 & 0.020 & 0 & 1.67 & 1 & 0.031 \\
\hline $\mathrm{CP}$ & 138 & 4.06 & 0.006 & 0 & 6.55 & 0.40 & 0.004 \\
\hline
\end{tabular}

a Fixed-effects likelihood; $d \mathrm{~N}=$ nonsynonymous and $d \mathrm{~S}=$ synonymous.

${ }^{\mathrm{b}}$ Mixed-effects model of evolution. Values of $\beta^{-}$and $\beta^{+}$mean $d \mathrm{~N}$ substitution rates to each site, one that is $\leq d \mathrm{~S}$ and one that is unrestricted, respectively. Values of $p^{+}$indicate the proportion of branches estimated to be part of the $d \mathrm{~N}$ substitution rate class.

${ }^{c} \mathrm{MP}=$ movement protein and $\mathrm{CP}=$ coat protein. 
genome sequences of CMV populations are required for understanding the genetic structure of CMV populations and their evolutionary histories. In the present study, we investigated the molecular genetic structure of CMV populations at a geographic scale based on analyses of full genome sequences of a large number of CMV isolates from pepper.

Mixed infections with two or more viruses are known to be common in virus-infected crop fields $(3,12,18)$. Our field surveys also revealed that $62.3 \%$ of the collected pepper tissues were mixed infected with at least two viruses (i.e., CMV + BBWV2, $\mathrm{CMV}+$ PepMoV, BBWV2 + PepMoV, or CMV + BBWV2 + PepMoV). In many cases, mixed viral infections cause synergistic symptom enhancement, resulting in a great loss of yield and commercial value of crops. Synergistic symptom responses by coinfection of CMV with other viruses, including Zucchini yellow mosaic virus, Tobacco necrosis virus, and Abutilon mosaic virus, have been reported (34-36). Sometimes the enhancement of the synergistic symptom expression is related to an increase in titer of the infecting viruses (30). We also observed synergistic symptom responses on the mixed-infected pepper samples, especially with PepMoV, which is a Potyvirus sp. (data not shown).

In this study, we determined the complete genome sequences of $45 \mathrm{CMV}$ isolates from pepper and analyzed the genetic diversity and phylogenetic structure of this population. Analyses of the pairwise nucleotide and deduced amino acid similarities among the CMV isolates revealed that nucleotide variations were distributed throughout the entire genome but the $5^{\prime}$ and $3^{\prime}$ UTRs of RNA2 and the $5^{\prime}$ UTR and central intercistronic region of RNA3 were significantly more variable than the protein-coding regions (Fig. 2). This suggests that the protein-coding regions are under stronger evolutionary constraint than the noncoding regions. Many of viral proteins are compact and play essential roles in the virus life cycle. Thus, genetic flexibility of the viral protein-coding regions is likely to be very limited. In addition, our analyses revealed that the $2 \mathrm{~b}$ gene of CMV is under weaker purifying selection than the other genes in the CMV population, indicating the $2 \mathrm{~b}$ protein may be structurally or functionally more flexible. It has been considered that different evolutionary dynamics for different genomic regions are closely associated with functional or structural constraints on conserved regions (10). Overall, plant viruses tend to have greater evolutionary constraints on the proteins involved in replication (i.e., the 1a and 2a proteins) and less conservation of MPs and capsid proteins.

Phylogenetic analyses of the $45 \mathrm{CMV}$ isolates from pepper provide a framework for classifying the CMV subpopulations according to geographic origins. This CMV collection can be largely divided into three subpopulations based on the phylogenetic analyses of RNA1 sequences (Fig. 3). This phylogenetic classification is highly correlated with geographic clustering of the CMV subpopulations according to latitude (Fig. 4). The geographic clustering of the CMV subpopulations in Korea was further supported by SAMOVA analyzed by the SAMOVA program (Fig. 4; Table 4). Interestingly, a recent study performed by Ben Tamarzizt et al. (2) showed geographic localization of CMV subpopulations in Tunisia. It was suggested that there was a high genetic differentiation between two local CMV subpopulations in Tunisia and this differentiation was associated with the localities of sampling (2). Although more detailed examinations are required to clarify the relationship between phylogenetic and geographic clustering, it is possible that temperature affects the geographic colonization of CMV in pepper fields in Korea in relation to pepper cultivars cultivated in each local area and ranges of alternate hosts and insect vectors.

Analyses of the whole CMV population detected a total of 11 possible positively selected sites in the 1a-, 2a-, MP-, and CPcoding genes (Table 5). Several studies have shown that the CMV proteins such as $1 \mathrm{a}$ and $2 \mathrm{a}$ function as an elicitor for plant defense responses $(6,15-17)$. In particular, a recent study showed that a
CMV isolate isolated from a pepper cultivar harboring the Cmrl gene, which confers resistance to $\mathrm{CMV}$, contained mutations in the 1a protein (15), indicating that CMV 1a protein may be a target for resistance responses in pepper. In this regard, the positive selections found in the CMV population (Table 5) might be the result of adaptation of CMV to resistant plants or novel hosts.

In the present study, we have examined the genetic structure and diversity of the CMV population from pepper based on analyses of full genome sequences. Our results showed that each genomic region is under different evolutionary constraints in the population of CMV from pepper. Consistent with previous studies $(8,13,24,25,31)$, our complete genome sequence-based analyses also suggested that reassortment might have occurred in the CMV Korean population. Conclusively, our study suggests that analyses of viral populations on a restricted geographic scale can provide other detailed aspects of evolution that cannot be determined from studies on a worldwide-scale.

\section{ACKNOWLEDGMENTS}

This work was supported by a grant from the Agenda Program (PJ008537), Rural Development Administration, and Republic of Korea. M.-K. Kim and J.-K. Soo contributed equally to this work. We thank M. J. Roossinck for helpful discussions and editorial comments.

\section{LITERATURE CITED}

1. Abdalla, O., Desjardins, P., and Dodds, J. 1991. Identification, disease incidence, and distribution of viruses infecting peppers in California. Plant Dis. 75:1019-1023.

2. Ben Tamarzizt, H., Montarry, J., Girardot, G., Fakhfakh, H., Tepfer, M., and Jacquemond, M. 2013. Cucumber mosaic virus populations in Tunisian pepper crops are mainly composed of virus reassortants with resistance-breaking properties. Plant Pathol. 62:1415-1428.

3. Choi, G.-S., Kim, J.-H., Lee, D.-H., Kim, J.-S., and Ryu, K.-H. 2005. Occurrence and distribution of viruses infecting pepper in Korea. Plant Pathol. J. 21:258-261.

4. Choi, H.-S., Lee, S.-H., Kim, M.-K., Kwak, H.-R., Kim, J.-S., Cho, J.-D., and Choi, G.-S. 2010. Occurrence of virus diseases on major crops in 2009. Res. Plant Dis. 16:1-9.

5. Davino, S., Panno, S., Rangel, E. A., Davino, M., Bellardi, M. G., and Rubio, L. 2012. Population genetics of Cucumber mosaic virus infecting medicinal, aromatic and ornamental plants from northern Italy. Arch. Virol. 157:739-745.

6. Diveki, Z., Salanki, K., and Balazs, E. 2004. The necrotic pathotype of the Cucumber mosaic virus (CMV) ns strain is solely determined by amino acid 461 of the 1a protein. Mol. Plant-Microbe Interact. 17:837-845.

7. Dupanloup, I., Schneider, S., and Excoffier, L. 2002. A simulated annealing approach to define the genetic structure of populations. Mol. Ecol. 11:2571-2581.

8. Fraile, A., Alonso-Prados, J. L., Aranda, M. A., Bernal, J. J., Malpica, J. M., and Garcia-Arenal, F. 1997. Genetic exchange by recombination or reassortment is infrequent in natural populations of a tripartite RNA plant virus. J. Virol. 71:934-940.

9. Garcia-Arenal, F., Escriu, F., Aranda, M. A., Alonso-Prados, J. L., Malpica, J. M., and Fraile, A. 2000. Molecular epidemiology of Cucumber mosaic virus and its satellite RNA. Virus Res. 71:1-8.

10. Garcia-Arenal, F., Fraile, A., and Malpica, J. M. 2001. Variability and genetic structure of plant virus populations. Annu. Rev. Phytopathol. 39:157-186.

11. Garcia-Arenal, F., and McDonald, B. A. 2003. An analysis of the durability of resistance to plant viruses. Phytopathology 93:941-952.

12. Green, S. K., and Kim, J.-S. 1991. Characteristics and control of viruses infecting peppers : A literature review. Tech. Bull. 18:60.

13. Jacquemond, M. 2012. Cucumber mosaic virus. Adv. Virus Res. 84:439504.

14. Joannon, B., Lavigne, C., Lecoq, H., and Desbiez, C. 2010. Barriers to gene flow between emerging populations of Watermelon mosaic virus in southeastern France. Phytopathology 100:1373-1379.

15. Kang, W. H., Seo, J. K., Chung, B. N., Kim, K. H., and Kang, B. C. 2012. Helicase domain encoded by Cucumber mosaic virus RNA1 determines systemic infection of Cmr1 in pepper. PLoS One 7:e43136.

16. Karasawa, A., Okada, I., Akashi, K., Chida, Y., Hase, S., Nakazawa-Nasu, Y., Ito, A., and Ehara, Y. 1999. One amino acid change in Cucumber mosaic virus RNA polymerase determines virulent/avirulent phenotypes on cowpea. Phytopathology 89:1186-1192. 
17. Kim, C. H., and Palukaitis, P. 1997. The plant defense response to cucumber mosaic virus in cowpea is elicited by the viral polymerase gene and affects virus accumulation in single cells. EMBO J. 16:4060-4068.

18. Kim, J.-S., Lee, S.-H., Choi, H.-S., Kim, M.-K., Kwak, H.-R., Nam, M., Kim, J.-S., Choi, G.-S., Cho, J.-D., Cho, I.-S., and Chung, B.-N. 2011. Occurrence of Virus Diseases on Major Crops in 2010. Res. Plant Dis. 17:334-341.

19. Kimura, M. 1980. A simple method for estimating evolutionary rates of base substitutions through comparative studies of nucleotide sequences. J. Mol. Evol. 16:111-120.

20. Kosakovsky Pond, S. L., and Frost, S. D. 2005. Not so different after all: A comparison of methods for detecting amino acid sites under selection. Mol. Biol. Evol. 22:1208-1222.

21. KSPP. 2009. List of Plant Diseases in Korea, 5th ed. W.-G. Kim and H.-M. Koo, eds. The Korean Society of Plant Pathology, Suwon, Korea.

22. Larkin, M. A., Blackshields, G., Brown, N. P., Chenna, R., McGettigan, P. A., McWilliam, H., Valentin, F., Wallace, I. M., Wilm, A., Lopez, R., Thompson, J. D., Gibson, T. J., and Higgins, D. G. 2007. Clustal W and Clustal X version 2.0. Bioinformatics 23:2947-2948.

23. Li, W. H. 1993. Unbiased estimation of the rates of synonymous and nonsynonymous substitution. J. Mol. Evol. 36:96-99.

24. Lin, H. X., Rubio, L., Smythe, A., Jiminez, M., and Falk, B. W. 2003. Genetic diversity and biological variation among California isolates of Cucumber mosaic virus. J. Gen. Virol. 84:249-258.

25. Lin, H. X., Rubio, L., Smythe, A. B., and Falk, B. W. 2004. Molecular population genetics of Cucumber mosaic virus in California: Evidence for founder effects and reassortment. J. Virol. 78:6666-6675.

26. Maddison, W. P., and Maddison, D. R. 1989. Interactive analysis of phylogeny and character evolution using the computer program MacClade. Folia Primatol. (Basel) 53:190-202.

27. Murrell, B., Wertheim, J. O., Moola, S., Weighill, T., Scheffler, K., and Kosakovsky Pond, S. L. 2012. Detecting individual sites subject to episodic diversifying selection. PLoS Genet. 8:e1002764.

28. Palukaitis, P., and Garcia-Arenal, F. 2003. Cucumoviruses. Adv. Virus Res. 62:241-323.

29. Pamilo, P., and Bianchi, N. O. 1993. Evolution of the Zfx and Zfy genes: Rates and interdependence between the genes. Mol. Biol. Evol. 10:271281.

30. Pruss, G., Ge, X., Shi, X. M., Carrington, J. C., and Bowman Vance, V. 1997. Plant viral synergism: The potyviral genome encodes a broad-range pathogenicity enhancer that transactivates replication of heterologous viruses. Plant Cell 9:859-868.

31. Roossinck, M. J. 2002. Evolutionary history of Cucumber mosaic virus deduced by phylogenetic analyses. J. Virol. 76:3382-3387.

32. Tamura, K., Peterson, D., Peterson, N., Stecher, G., Nei, M., and Kumar, S. 2011. MEGA5: Molecular evolutionary genetics analysis using maximum likelihood, evolutionary distance, and maximum parsimony methods. Mol. Biol. Evol. 28:2731-2739.

33. Tan, L., Lemey, P., Houspie, L., Viveen, M. C., Jansen, N. J. G., Loon, A. M., Wiertz, E., Bleek, G. M., Martin, D. P., and Coenjaerts, F. E. 2012. Genetic variability among complete human respiratory syncytial virus subgroup A genomes: Bridging molecular evolutionary dynamics and epidemiology. PLoS One 7:e51439. doi:10.1371/journal.pone.0051439

34. Wang, Y., Gaba, V., Yang, J., Palukaitis, P., and Gal-On, A. 2002. Characterization of synergy between Cucumber mosaic virus and potyviruses in cucurbit hosts. Phytopathology 92:51-58.

35. Wege, C., and Siegmund, D. 2007. Synergism of a DNA and an RNA virus: Enhanced tissue infiltration of the begomovirus Abutilon mosaic virus (AbMV) mediated by Cucumber mosaic virus (CMV). Virology 357:10-28.

36. Xi, D., Feng, H., Lan, L., Du, J., Wang, J., Zhang, Z., Xue, L., Xu, W., and Lin, H. 2007. Characterization of Synergy between Cucumber mosaic virus and Tobacco necrosis virus in Nicotiana benthamiana. J. Phytopathol. 155:570-573. 